\title{
Molecular study and overexpression of the Clostridium cellulolyticum celf cellulase gene in Escherichia coli
}

\author{
Corinne Reverbel-Leroy, ${ }^{1}$ Anne Belaich, ${ }^{1}$ Alain Bernadac, ${ }^{2}$ \\ Christian Gaudin, ${ }^{1}$ Jean-Pierre Belaich ${ }^{1,3}$ and Chantal Tardif ${ }^{1,3}$ \\ Author for correspondence: Chantal Tardif. Tel: +3391 16 43 40. Fax: +3391713321. \\ e-mail: gaudin@ir1cbm.cnrs-mrs.fr
}

1,2 Bioénergétique et Ingéniérie des protéines ${ }^{1}$ and Laboratoire d'Ingéniérie et

Dynamique des Systèmes Membranaires², Centre

National de la Recherche Scientifique, 31 chemin Joseph Aiguier, BP71, 13402 Marseille Cedex 20, France

3 Université de Provence, Marseille, France 3
The Celf-encoding sequence was isolated from Clostridium cellulolyticum genomic DNA using the inverse PCR technique. The gene lies between cipC (the gene encoding the cellulosome scaffolding protein) and ce/C (coding for the endoglucanase $\mathrm{C}$ ) in the large cel cluster of this mesophilic cellulolytic Clostridium species. Comparisons between the deduced amino acid sequence of the mature Celf (693 amino acids, molecular mass 77626) and those of other $\beta$-glycanases showed that this enzyme belongs to the recently proposed family $L$ of cellulases (family $\mathbf{4 8}$ of glycosyl hydrolases). The protein was overproduced in Escherichia coli using the $\mathrm{T7}$ expression system. It formed both cytoplasmic and periplasmic inclusion bodies when induction was performed at $37^{\circ} \mathrm{C}$. Surprisingly, the protein synthesized from the cytoplasmic production vector was degraded in the lon protease-deficient strain BL21(DE3). The induction conditions were optimized with regard to the concentration of inductor, cell density, and temperature and time of induction in order to overproduce an active periplasmic protein (CelFp) which was both soluble and stable. It was collected using the osmotic shock method. The enzymic degradation of various cellulosic substrates by CelFp was studied. CelFp degraded swollen Avicel more efficiently than substituted soluble CMcellulose or crystalline Avicel and was not active on xylan. Its activity is therefore quite different from that of endoglucanases, which are most active on CM-cellulose.

Keywords: Clostridium cellulolyticum, cellulase, periplasmic inclusion bodies, overproduction

\section{INTRODUCTION}

Cellulose is the major component of plant cell walls and is consequently the most abundant biopolymer in the world. Clostridium cellulolyticum strain ATCC 35319 was isolated from compost (Petitdemange et al., 1984) and the physio-

Abbreviation : $p$-NP, para-nitrophenyl

Gene nomenclature. In our previous work, the genes coding for the cellulosome components of Clost. cellulolyticum were referred to as ce/CC. In accordance with the standard rules of bacterial genetic nomenclature, these have been renamed cel in the present paper. For example, ce/CCF is now referred to as celf.

The GenBank accession number for the nucleotide sequence reported in this paper is U30321. logical properties of this organism have been studied (Giallo et al., 1983). This Gram-positive, mesophilic, anaerobic Clostridium species is a true cellulolytic organism, which can use cellulose as its sole source of carbon and energy (Giallo et al., 1985).

It has recently been established that Clost. cellulolyticum possesses a macromolecular cellulolytic system, which has been called a cellulosome (Faure et al., 1987; Madarro et al., 1991). Cellulosomes were first described in Clostridium thermocellum (Lamed et al., 1983a), a Gram-positive, thermophilic, anaerobic bacterium. SDS-PAGE analysis of these multiprotein complexes from two strains of Clost. thermocellum (YS and ATCC 27405) revealed the existence of two major components called $\mathrm{S} 1(210 \mathrm{kDa})$ and $\mathrm{S} 8$ $(75 \mathrm{kDa})$ (Lamed et al., $1983 \mathrm{~b})$, or $\mathrm{S}_{\mathrm{L}}(250 \mathrm{kDa})$ and $\mathrm{S}_{\mathrm{S}}$ 
(82 kDa) (Wu \& Demain, 1988), respectively. Most of the cellulosomal subunits in Clost. thermocellum have been found to be cellulases which exhibit endoglucanase activity (Lamed et al., 1983a,b), except for one true xylanase (Grépinet et al., 1988), one lichenase (Schimming et al., 1991) and the major components S1 and S8. S8 and $\mathrm{S}_{\mathrm{S}}$ were shown to be cellobiohydrolases (Morag et al., 1991; Kruus et al., 1995b).

The largest component, $\mathrm{S} 1$ (or $\mathrm{S}_{\mathrm{L}}$ ), recently renamed CipA (for cellulosome integrating protein) (Fujino et al., 1993a), has been found to be a scaffolding protein (Salamitou et al., 1992; Gerngross et al., 1993) around which the various catalytic components are anchored, and also to promote the binding of the cellulosome to cellulose. The determinant involved in the attachment of the catalytic subunits to CipA has been identified as a duplicated segment of 22 residues, which is conserved in all the cellulosome subunits identified so far (Tokatlidis $e t$ al., 1991).

To date, seven genes coding for components of the Clost. cellulolyticum cellulosome have been identified. cel $A$ (Faure et al., 1989) and celD (Shima et al., 1991) were described as monocistronic transcription units. More recently, a cluster of cel genes was described (Bagnara-Tardif et al., 1992) including ORF1, celC, celG and celE, with celC and $c e l G$ associated in a polycistronic transcription unit. The $\mathrm{cel} A$ and $c e l C$ gene products have been extensively characterized (Bélaich et al., 1992; Fierobe et al., 1993; Fierobe $e t$ al., 1991) and the three-dimensional structure of CelA has been established (Ducros $e t$ al., 1995; Roig et al., 1993). A very similar cluster has been described for the cellulase genes of Clostridium josui, in which the order and sequence of genes corresponding to ORF1, $\mathrm{celC}$ and $c e l G$ are highly conserved (Fujino et al., 1993b). Clost. josui and Clost. cellulolyticum are probably two strains of the same species.

In the present paper, we describe the cloning, sequencing and expression of the $c e l F$ gene corresponding to ORF1 in the $c e$ lgene cluster. When celF was expressed in Escherichia coli under standard conditions, the recombinant protein aggregated and formed inclusion bodies. After optimizing the induction conditions, a mature form of CelF was produced, which was both soluble and stable. CelF hydrolysed cellulose (not xylan), but was poorly active on substituted cellulose. CelF may be the equivalent, in the Clost. cellulolyticum cellulosome, of the S8/CelS component of Clost. thermocellum, and probably corresponds to the major $72 \mathrm{kDa}$ Avicel-adsorbed subunit described by Madarro et al. (1991).

In addition, another ORF located upstream from $c e l F$ was identified as a cip gene of the Clost. cellulolyticum cellulosome.

\section{METHODS}

Bacterial strains and vectors. Clost. cellulolyticum strain ATCC 35319 was used as the source of genomic DNA. The E. coli strains used in this study were DH5 $\alpha$ (Bethesda Research Laboratories), which was used as the host for cloning plasmid

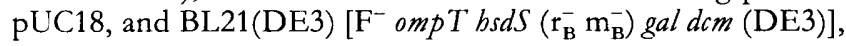

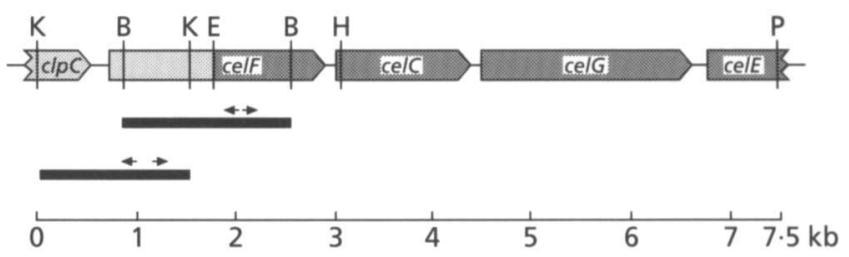

Fig. 1. Map of the cel gene cluster from Clost. cellulolyticum. Shaded areas indicate previously determined cel gene sequences. Thick bars and arrows indicate the fragments and primers used for inverse PCR. B, BamHI; E, EcoRI; H, HindIII; K, Kpnl; P, Pvull.

which was used as the host for the expression vector pET22b $(+)$ (Novagen).

Growth conditions. Clost. cellulolyticum was grown anaerobically at $32{ }^{\circ} \mathrm{C}$ on basal medium supplemented with cellobiose as the carbon and energy source (Giallo et al., 1983).

E. coli $\mathrm{DH} 5 \alpha$ was grown at $37^{\circ} \mathrm{C}$ in Luria Bertani medium supplemented with ampicillin $\left(100 \mu \mathrm{g} \mathrm{ml}^{-1}\right)$ when required.

E. coli BL21(DE3) was grown under the same conditions, except that the growth temperature and IPTG concentration were modulated to provide optimal conditions for heterologous protein production.

DNA isolations and manipulations. Clost. cellulolyticum genomic DNA was purified as described by Quiviger et al. (1982). Smallscale plasmid purification from E. coli was performed using the alkaline lysis method (Engebrecht et al., 1991). Plasmids for DNA sequencing reactions were purified by using the Qiagen kit.

PCR technique used in cloning experiments. The celF gene was amplified from Clost. cellulolyticum genomic DNA by performing inverse PCR (Ochman et al., 1990) in the presence of Taq DNA polymerase (Boehringer Mannheim). Divergent primers for amplification (Fig. 1) were derived from the previously determined sequence of the $3^{\prime}$ region of the gene (Bagnara-Tardif et al., 1992). PCR fragments were cloned into pUC18.

DNA sequence analysis. Nested deletions of recombinant plasmids were prepared as described previously (Bagnara-Tardif et al., 1992). DNA was sequenced using the dideoxy chain termination method (Sanger et al., 1977), with $\left[{ }^{35} \mathrm{~S}\right] \mathrm{dATP} \alpha \mathrm{S}$ and a Sequenase 2.0 sequencing kit (US Biochemicals). Two different clones from two independent PCR events were sequenced to ensure that PCR did not induce any base exchange. The entire sequence described was determined on both strands. Analysis of the sequence was carried out using the DNASIs program (Pharmacia). Protein sequences were compared with the databanks using the BLASTP program from NCBI (Altschul et al., 1990).

Expression of celF in $\boldsymbol{E}$. coli. The structural gene was amplified by PCR with restriction-site-containing primers ( NcoI at the start of the gene and $X b o I$ at the end) to facilitate in-frame cloning into the expression vector. The oligo primer sequences were $5^{\prime}$ catgccatgGCTTCAAGTCCTGCAAAC $3^{\prime}$ (5' end) and 5'ccgctcgagTTGGATAGAAAGAAGTGC3' (3' end), with sequences complementary to the target DNA given in upper case letters and restriction sites in bold face type. After a digestion stage with $\mathrm{NcoI}$ and $\mathrm{XboI}$, the PCR-amplified fragment 
was ligated into NcoI- and XboI-digested pET22b $(+)$. The coding sequence of $c e l F$ was fused in-frame with an upstream sequence encoding the PelB leader peptide, and with a downstream sequence encoding six histidine residues (HisTag). This gene fusion was under the control of the T7 promoter. The resulting phasmid was named pETFp. Another expression vector (pETFc) was obtained by deleting the sequence encoding PelB leader peptide. pETFp was digested with $N c o$ I and $N d e I$ and repaired with the Klenow fragment of DNA polymerase I. Since the phasmid was not stably maintained in BL21(DE3), E. coli DH5 $\alpha$ was transformed with the recombinant phasmids prior to being stored. The $\mathrm{pETFp}$ and pETFc constructs were verified by performing restriction site and DNA sequence analyses. Recombinant proteins were expressed in E. coli BL21(DE3).

To determine the solubility of the expressed proteins and their subcellular localization (i.e. cytoplasmic and/or periplasmic), cells were grown at $37^{\circ} \mathrm{C}$ to a cell density equivalent to an $\mathrm{OD}_{600}$ of 1 and IPTG was then added to a final concentration of $0.4 \mathrm{mM}$. Two hours after starting induction, the cells were harvested by centrifugation and washed in $20 \mathrm{mM}$ Tris $/ \mathrm{HCl}$, $\mathrm{pH}$ 7.5. Aliquots of cell suspensions were used for electron microscopy and the remainder were disrupted in a French press. The suspensions obtained were centrifuged for $20 \mathrm{~min}$ at $14000 \mathrm{~g}$. The pellets were washed twice in $20 \mathrm{mM}$ Tris $/ \mathrm{HCl}$, $\mathrm{pH} 7 \cdot 5$. Aliquots of insoluble fractions were washed with $6 \mathrm{M}$ urea before being dissolved in $8 \mathrm{M}$ urea. All fractions were analysed by SDS-PAGE.

Aliquots of insoluble fractions were suspended in $6 \mathrm{M}$ guanidinium chloride; $100 \mathrm{mM}$ sodium phosphate; $10 \mathrm{mM}$ Tris $/ \mathrm{HCl}, \mathrm{pH}$ 8. After $1 \mathrm{~h}$, solubilized proteins bearing the HisTag were purified by affinity chromatography on Ni-NTA resin (Novagen) according to the manufacturer's instructions.

To isolate soluble periplasmic proteins, cells were grown at $37^{\circ} \mathrm{C}$ to an $\mathrm{OD}_{600}$ of $1 \cdot 6-2 \cdot 4$. Cultures were then left to equilibrate at $17^{\circ} \mathrm{C}$ for $30 \mathrm{~min}$ before adding $40 \mu \mathrm{M}$ IPTG and then shaken overnight at $17^{\circ} \mathrm{C}$. Cells were centrifuged and resuspended in ice-cold buffer I $20 \mathrm{mM}$ Tris/ $\mathrm{HCl}, \mathrm{pH} 8 ; 20 \%$ $(\mathrm{w} / \mathrm{v})$ sucrose] at an $\mathrm{OD}_{600}$ of 5 , and incubated on ice for 10 $\mathrm{min}$. Cells were then pelleted by centrifugation at $16300 \mathrm{~g}$ at $4{ }^{\circ} \mathrm{C}$ for $2 \mathrm{~min}$ and osmotically shocked by resuspending in the same volume of ice-cold buffer II (20 mM Tris/ $\mathrm{HCl}, \mathrm{pH} 8)$. After incubating for $10 \mathrm{~min}$ on ice with gentle shaking, cells were centrifuged for $10 \mathrm{~min}$ at $10400 \mathrm{~g}\left(4^{\circ} \mathrm{C}\right)$. The supernatant, which constituted the periplasmic fraction, was concentrated in a $400 \mathrm{ml}$ Amicon concentrator before performing precipitation in the presence of ammonium sulfate at $80 \%$ saturation.

Electron microscopy of inclusion bodies. Cells were fixed in $2.5 \%(\mathrm{v} / \mathrm{v})$ glutaraldehyde and $2 \%(\mathrm{w} / \mathrm{v})$ osmium tetroxide, dehydrated in ethanol and embedded in Epon. Ultrathin sections were contrasted with aqueous uranyl acetate followed by lead citrate and examined with a Siemens Elmiskop 1A electron microscope.

$\mathbf{N}$-terminal amino acid sequence analysis. Recombinant proteins were analysed by SDS-PAGE $(7 \%, \mathrm{w} / \mathrm{v}$, acrylamide) and transferred onto a modified fibreglass membrane (Biometra). The membrane was stained with Ponceau red for protein band detection. The recombinant protein band on the membrane was excised and the $\mathrm{N}$-terminal amino acid sequence of the protein was determined using an Applied Biosystems 470 A sequence analyser.

Cellulase activity assays. Cellulase activity was assayed by mixing $1 \mathrm{ml}$ of an appropriate enzyme dilution with $4 \mathrm{ml}$ of $1 \%$ (w/v) CM-cellulose (medium viscosity; Sigma-Aldrich), Avicel cellulose (Fluka), swollen cellulose [phosphoric-acid-swollen Avicel cellulose (Wood, 1988)] or xylan (oat spelts), in $25 \mathrm{mM}$ potassium phosphate, $\mathrm{pH} 7 \cdot 0$. The amount of reducing sugars released in $1 \mathrm{ml}$ was measured at various incubation times using the method described by Park \& Johnson (1949) after removing solids by centrifugation, if required. One unit (IU) of cellulase activity corresponds to $1 \mu \mathrm{mol} \mathrm{D}$-glucose equivalent released $\min ^{-1}$.

$p$-Nitrophenyl ( $p$-NP)-cellobioside, $p$-NP-lactoside, $p$-NP-glucoside and $p$-NP-xyloside (Sigma) were also tested. Samples $(900 \mu \mathrm{l})$ of a solution containing $1 \mathrm{~g}$ chromophoric substrate $\mathrm{l}^{-1}$ in $25 \mathrm{mM}$ potassium phosphate, $\mathrm{pH} 7.0$ were mixed with $100 \mu \mathrm{l}$ diluted enzyme and incubated at $37^{\circ} \mathrm{C}$. The release of $p$ nitrophenol was followed by monitoring $A_{400}$. One unit of activity was defined as that corresponding to $1 \mu \mathrm{mol} p$ nitrophenol liberated $\mathrm{min}^{-1}$.

The protein concentration was determined using the Lowry method with BSA as the standard.

\section{RESULTS \\ Cloning of the celf gene}

In a previous study (Bagnara-Tardif et al., 1992), we characterized part of a cel gene cluster of Clost. cellulolyticum. A truncated ORF preceding the $c e l C$ gene encoded a polypeptide whose $\mathrm{C}$-terminal amino acid sequence included the reiterated segment typical of the $C$. cellulolyticum proteins involved in cellulolysis. The missing part of the ORF, now termed $c e l F$, was cloned in two steps of inverse PCR (Fig. 1). Flanking DNA (1009 bp) was recovered from the first $1695 \mathrm{bp} \mathrm{BamHI}$ fragment. The $847 \mathrm{bp}$ region upstream from this fragment was obtained by the same method from a 1641 bp KpnI fragment.

\section{Sequence analysis of the celf gene}

The celF coding sequence with a length of 2169 nt was found to be present within a $3 \mathrm{~kb}$ fragment beginning with a KpnI site and ending in a HindIII site (Fig. 2). The ORF encodes a polypeptide containing 722 amino acids with a calculated molecular mass of $80550 \mathrm{Da}$. The coding sequence is preceded by a typical ribosome-binding site. As expected, the $\mathrm{N}$-terminal peptide sequence exhibits the characteristics of a 29 residue leader peptide. The sequence $\mathrm{Ile}_{27}-\mathrm{X}_{28}-\mathrm{Ala}_{29}-\mathrm{Ala}_{30}$ might constitute the consensus motif for leader peptide excision (Perlman \& Halvorson, 1983). The mature protein consisting of 693 amino acids was found to have a calculated molecular mass of $77626 \mathrm{Da}$. Comparisons with sequences in the EMBLGenBank database revealed that CelF (and the polypeptide encoded by Clost. josui ORF1) were very similar to three proteins: (i) the cellobiohydrolase CelS of Clost. thermocellum ATCC 27405 (Wang et al., 1993; GenBank accession member L06942), which is probably identical to the S8 subunit of the cellulosome of Clost. thermocellum YS (Morag et al., 1993); (ii) the C-terminal domain of Caldocellum saccharolyticum endoglucanase CelA (Lüthi et 
KpnI

1 GGTACCGACTTTACAGTGTCAAATAATGTTGTAACAATCTCAAAGAGCTATTTGAGCACT $\begin{array}{llllllllllllllllllll}G & T & D & F & T & V & S & N & N & V & V & T & I & S & K & S & Y & L & \$ & T\end{array}$

61 TTAGCAGTTGGTTCAAAGACACTGACATTTGATTTTGGTGTTACAAATAATCCAG:ITCTG $\begin{array}{llllllllllllllllllll}\text { L } & A & V & G & S & K & T & \text { L } & T & \text { F } & \text { D } & \text { F } & G & \text { V } & \text { T } & \text { N } & \text { N } & \text { P } & \text { V } & \text { L }\end{array}$

121 ACTTTAACAATCACTGACTCTACACCTGTTGTTACAGGACTTGGAGTAAAGATTGCTTCA $\begin{array}{llllllllllllllllllll}T & L & T & I & T & D & S & T & P & V & V & T & G & L & G & V & K & I & A & S\end{array}$

181 GTAACAGGTAAAACTGGTGATACTATAACAGTACCTGTAACTCTGAGCAATGTTG:.TAAA $\begin{array}{lllllllllllllllllllllllllll}V & T & G & K & T & G & D & T & I & T & V & P & V & T & L & S & N & V & V & K\end{array}$

241 TCAGGTAATGTAGgAACATGTAATTTCTATATTACATACGATGCAAGCATGCTGCAGGCA $\begin{array}{llllllllllllllllllllll}S & G & N & V & G & T & C & N & F & Y & I & T & Y & D & A & S & M & L & Q & A\end{array}$

301 GTATCAGCAACAGCTGGTGACATAGTACTCAATGCACCAGTTAACTTCTCAAGCAGCATC $\begin{array}{llllllllllllllllllll}V & S & A & T & A & G & D & I & V & \text { L } & N & A & P & V & N & F & S & S & S & I\end{array}$

361 AACGCAACAACTGGTACAATCAGTATCCTTTTCCTGGATAACACTATAGGTGATCAGCTC $\begin{array}{lllllllllllllllllllll}N & A & T & T & G & T & I & S & I & \text { L } & \text { F } & \text { L } & \text { D } & \text { N } & \text { T } & \text { I } & G & \text { D } & Q & \text { L }\end{array}$

421 ATTACCAGCGATGGAGTAGTTGCTAATCTTACATTTAAAGTAGTAGGACTTCAAGCACA $\begin{array}{llllllllllllllllllll}I & T & S & D & G & V & V & A & N & I & T & F & K & V & V & G & T & S & S & T\end{array}$

481 ACAACTCCTATCGCATTTAAAGCAGGCGGAGCTTTCGGTAATGGAAACATGTCTAAAATT

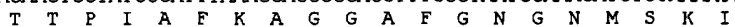

541 TCTGATATTACATTCACAAACGGAAGTGCAAAACTTAATTAATTATTGAATTTAAATTTT

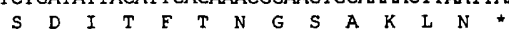

601 CCATACTTTATGGCATCAAGCCATAAAGTATGGAGTAAAAAAACATATGAGCAGATTTTA $-30 \mathrm{kcal} / \mathrm{mol}$

661 CTCTGCCATAAAAATTCAAAGAATAAGGAAGGTGTAAAATGAGTAAGAATTTTAAAAGAG $M \quad S \quad K \quad N \quad F \quad K \quad R$

721 TAGGAGCAGTTGCAGTTGCTGCTGCAATGTCATTATCTATAATGGCAACAACCAGCATAA $\begin{array}{lllllllllllllllllllll}8 & V & G & A & V & A & V & A & A & A & M & S & \text { L } & \text { S } & \text { I } & M & \text { A } & \text { T } & \text { T } & \text { S } & \text { I }\end{array}$

781 ATGCAGCTTCAAGTCCTGCAAACAAGGTGTACCAGGATCGTTTTGAATCCATGTACAGCA $\begin{array}{lllllllllllllllllllllll}28 & N & A & A & S & S & P & A & N & K & V & Y & Q & D & R & F & E & S & M & Y & S\end{array}$ $\uparrow$

841 AGATTAAGGATCCTGCAAACGGATACTTCAGTGAACAGGGAATTCCTTACCACTCAATTG

$\begin{array}{lllllllllllllllllllll}48 & K & I & K & D & P & A & N & G & Y & \text { F } & \text { S } & \text { E } & Q & G & I & P & Y & H & S & I\end{array}$

901 AAACACTGATGGTCGAAGCTCCTGACTACGGACATGTTACAACAAGTGAAGCTATGTCCT

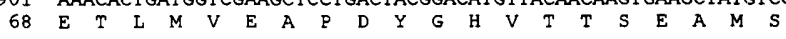

961 ATTATATGTGGTTGGAAGCAATGCACGGAAGATTTTCAGGAGATTTTACAGGTTTTGATA

$\begin{array}{llllllllllllllllllllll}88 & \text { Y } & \text { Y } & \text { M } & \text { W } & \text { L } & \text { E } & \text { A } & \text { M } & \text { H } & \text { G } & \text { R } & \text { F } & \text { S } & \text { G } & \text { D } & \text { F } & \text { T } & \text { G } & \text { F } & \text { D }\end{array}$

1023 AGTCTTGGTCTGTTACCGAACAGTATTTGATCCCAACAGAAAAGGATCAGCCCAATACAA

$\begin{array}{lllllllllllllllllllll}108 & K & S & W & S & V & T & E & Q & Y & L & I & P & T & E & K & D & Q & P & N & T\end{array}$

1081 GTATGAGCAGATATGATGCTAACAAACCGGCTACATACGCTCCGGAATTTCAGGACCCAA $\begin{array}{lllllllllllllllllllll}128 & \mathrm{~S} & \mathrm{M} & \mathrm{S} & \mathrm{R} & \mathrm{Y} & \mathrm{D} & \mathrm{A} & \mathrm{N} & \mathrm{K} & \mathrm{P} & \mathrm{A} & \mathrm{T} & \mathrm{Y} & \mathrm{A} & \mathrm{P} & \mathrm{E} & \mathbf{F} & \mathrm{Q} & \mathrm{D} & \mathrm{P}\end{array}$

1141 GCAAGTATCCTTCTCCGTTGGATACTAGTCAACCTGTTGGTAGAGATCCAATCAACTCAC

$\begin{array}{lllllllllllllllllllll}148 & S & K & Y & P & S & P & L & D & T & S & Q & P & V & G & R & D & P & I & N & S\end{array}$

1201 AATTGACTTCAGCATACGGAACAAGCATGCTGTATGGAATGCACTGGATACTTGACGTTG

$\begin{array}{llllllllllllllllllllll}168 & Q & \text { L } & \text { T } & \text { S } & \text { A } & \text { Y } & G & \text { T } & \text { S } & \text { M } & \text { L } & \text { Y } & G & M & \text { H } & \text { W } & \text { I } & \text { L } & \text { D } & \text { V }\end{array}$

1261 ATAACTGGTATGGATTTGGAGCAAGAGCTGATGGAACCTCCAAGCCATCATATATCAATA

$\begin{array}{lllllllllllllllllllll}188 & D & N & W & Y & G & F & G & A & R & A & D & G & T & S & K & P & S & Y & I & N\end{array}$

1321 CTTTCCAAAGAGGTGAGCAGGAGTCAACTTGGGAAACCATACCTCAACCATGTTGGGATG

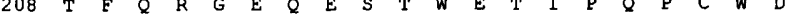

1381 AACATAAATTTGGTGGACAGTACGGATTCCTGGATCTCTTTACAAAGGATACAGGTACTC $\begin{array}{llllllllllllllllllllll}228 & \text { E } & \text { H } & \text { K } & \text { F } & G & G & Q & \text { Y } & \text { G } & \text { F } & \text { L } & \text { D } & \text { L } & \text { F } & \text { T } & \text { K } & \text { D } & \text { T } & \text { G } & \text { T }\end{array}$

1441 CGGCAAAGCAATTCAAATATACAAATGCTCCAGATGCTGATGCTCGTGCAGTTCAAGCAA $\begin{array}{lllllllllllllllllllll}248 & \text { P } & \text { A } & \text { K } & Q & \text { F } & \text { K } & \text { Y } & \text { T } & \text { N } & \text { A } & \text { P } & \text { D } & \text { A } & \text { D } & \text { A } & R & \text { A } & \text { V } & \text { Q } & \text { A }\end{array}$

1501 CTTACTGGGCTGATCAGTGGGCAAAAGACAAGGTAAGAGCGTAAGTACTAGCGTAGGTA $\begin{array}{lllllllllllllllllllll}268 & T & Y & W & A & D & O & \text { W } & A & K & E & 0 & G & K & S & V & S & T & S & V & G\end{array}$

1561 AGGCAACAAAGATGGGTGATTACCTTAGATATTCATTCTTTGATAAGTATTTCAGAAAGA

$\begin{array}{lllllllllllllllllllll}288 & K & A & T & K & M & G & D & Y & L & R & Y & S & F & F & D & K & Y & F & R & K\end{array}$

1621 TCGGACAACCTTCTCAGGCTGGTACCGGATATGATGCAGCACATTATCTGCTTTCATGGT

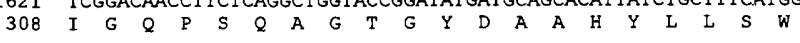

1681 ACTATGCATGGGGTGGTGGAATTGACTCTACCTGGTCTTGGATAATCGGTAGCAGTCATA

$\begin{array}{lllllllllllllllllllll}328 & Y & Y & A & W & G & G & G & I & D & S & T & W & S & W & I & I & G & S & S & H\end{array}$

1741 ATCATTTCGGTTACCAGAACCCATTTGCAGCTTGGGTACTTTCAACAGATGCAAACTTCA

$\begin{array}{lllllllllllllllllllll}348 & N & \text { H } & \text { F } & G & \text { Y } & \text { Q } & \text { N } & \text { P } & \text { F } & \text { A } & \text { A } & \text { W } & \text { V } & \text { L } & \text { S } & \text { T } & \text { D } & \text { A } & \text { N } & \text { F }\end{array}$

1801 AGCCTAAGTCATCAAATGGTGCATCAGACTGGGCAAAGAGTTTGGACAGACAGCTTGAAT

$\begin{array}{lllllllllllllllllllll}368 & K & \text { P } & K & \text { S } & \text { S } & \text { N } & G & \text { A } & \text { S } & \text { D } & \text { W } & \text { A } & \text { K } & \text { S } & \text { L } & \text { D } & \text { R } & \text { Q } & \text { L } & \text { E }\end{array}$

1861 TCTATCAGTGGTTGCAGTCAGCAGAAGGTGCTATTGCCGGTGGAGCTACAAACTCATGGA $\begin{array}{lllllllllllllllllllll}388 & \text { F } & \text { Y } & \text { Q } & \text { W } & \text { L } & \text { Q } & \text { S } & \text { A } & \text { E } & G & \text { A } & \text { I } & \text { A } & \text { G } & \text { G } & \text { A } & \text { T } & \text { N } & \text { S } & \text { W }\end{array}$

1921 ACGGACGTTATGAAGCAGTTCCTTCAGGTACATCAACATTCTATGGAATGGGTTATGTAG 408 N G R Y
1981 AAAACCCTGTATATGCTGACCCAGGTAGTAACACTTGGTTTGGTATGCAGGTATGGTCAA $\begin{array}{lllllllllllllllllllll}428 & E & N & P & V & Y & A & D & P & G & S & N & T & \text { W } & F & G & M & Q & V & W & S\end{array}$

2041 TGCAGCGTGTAGCTGAATTGTACTATAAGACTGGCGATGCCAGAGCTAAGAAACTCTTAG $\begin{array}{lllllllllllllllllllll}448 & M & O & R & V & A & E & L & Y & Y & K & T & G & D & A & R & A & K & K & L & L\end{array}$

2101 ACAAATGGGCAAAATGGATTAATGGCGAAATCAAGTTCAATGCTGACGGAACATTCCAGA $\begin{array}{lllllllllllllllllllll}468 & D & K & W & A & K & W & I & N & G & E & I & K & F & N & A & D & G & T & F & Q\end{array}$

2161 TTCCTAGCACAATTGATTGGGAAGGACAGCCGGATACTTGGAATCCAACACAGGGATACA

$\begin{array}{llllllllllllllllllllll}488 & I & P & S & T & I & D & W & E & G & Q & P & D & T & W & N & P & T & Q & G & Y\end{array}$

2221 CCGGAAATGCAAACTTGCATGTTAAAGTTGTTAACTATGGTACTGACCTAGGTTGTGCTT

$\begin{array}{llllllllllllllllllllll}508 & \text { T } & G & \text { N } & \text { A } & \text { N } & \text { L } & \text { H } & \text { V } & \text { K } & \text { V } & \text { V } & \text { N } & \text { Y } & \text { G } & \text { T } & \text { D } & \text { L } & \text { G } & \text { C } & \text { A }\end{array}$

2281 CTTCACTTGCAAACACATTGACTTACTATGCTGCTAAATCAGGAGATGAAACTTCAAGGC

$\begin{array}{lllllllllllllllllllll}528 & S & S & L & A & N & T & L & T & Y & Y & A & A & K & S & G & D & E & T & S & R\end{array}$

2341 AGAATGCACAGAAATTACTTGACGCTATGTGGAATAACTATAGCGATTCAAAGGGTATAT

$\begin{array}{llllllllllllllllllllll}548 & Q & N & A & Q & \text { K } & \text { L } & \text { L } & \text { D } & \text { A } & \text { M } & \text { W } & \text { N } & \text { N } & \text { Y } & \text { S } & \text { D } & \text { S } & \text { K } & \text { G } & \text { I }\end{array}$

2401 CAACTGTTGAACAGCGTGGTGATTACCATAGATTCCTTGATCAGGAAGTTTTTGTACCAG

$568 \mathrm{~S} T \mathrm{~T}$ E O R G D Y H R F L D O E V F V R

2461 CTGGTTGGACTGGAAAAATGCCTAACGGCGACGTAATCAAATCTGGTGTCAAGTTCATAG

$\begin{array}{lllllllllllllllllllll}588 & \text { A } & G & \text { W } & \text { T } & G & K & M & P & N & G & D & V & I & K & S & G & V & K & F & I\end{array}$

2521 ACATTCGTTCCAAGTACAAGCAGGATCCTGAATGGCAGACAATGGTTGCTGCATTACAGC

$\begin{array}{llllllllllllllllllllll}608 & D & I & R & S & K & Y & K & Q & D & P & E & W & Q & T & M & V & A & A & L & Q\end{array}$

2581 CAGGACAGGTTCCAACTCAGAGATTACACCGTTTCTGGGCTCAGAGTGAATTTGCAGTTG

$\begin{array}{llllllllllllllllllllll}628 & \text { A } & G & Q & V & P & T & Q & \text { R } & \text { L } & \text { H } & \text { R } & \text { F } & \text { W } & \text { A } & Q & \text { S } & \text { E } & \text { F } & \text { A } & \text { V }\end{array}$

2641 CAAATGGAGTTTATGCAATACTCTTCCCAGATCAAGGTCCAGAAAAATTATTGGGTGATG

$\begin{array}{llllllllllllllllllllllll}648 & A & N & G & V & Y & A & I & L & F & P & D & O & G & P & E & K & \text { L } & \text { L } & G & \text { D }\end{array}$

2701 TAAACGGTGACGAAACTGTAGACGCTATTGACCTTGCTATACTTAAAAAATATCTTTTAA

$\begin{array}{lllllllllllllllllllll}668 & V & N & G & D & E & T & V & D & A & I & D & \text { L } & A & I & \text { L } & \text { K } & \text { K } & \text { Y } & \text { L } & \text { L }\end{array}$

2761 ACAGCAGTACTACAATAAATACTGCAAATGCAGATATGAATAGTGATAATGCTATTGACG

688 N $\quad S \quad S \quad T$

2821 CTATTGACTATGCTCTTTTAAAGAAAGCACTTCTTTCTATCCAATAGTATTTAATACTAT

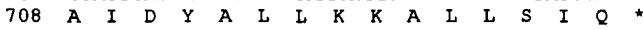

2881 GACGCATATGTAACCTTAAAGTCCGGACAGTATTTGGTTTGATTAAATTACTCATTCTTG

2941 TACTGTCCGGGCTTATGAGTTACAAAGAAAAAAAGAAAAGGATTAAGGTAAGAACATGAT

1

3001 HindII

$3 \mathrm{~K}$ G S S

Fig. 2. Nucleotide sequence and the predicted translation product of the Clost. cellulolyticum celf gene, including the upstream and downstream flanking regions ( $3^{\prime}$ end of cipC and $5^{\prime}$ end of $(e / C)$. Shine-Dalgarno sequences have been underlined. Restriction sites are shown above the nucleotide sequence. The inverted repeated sequence in the intergenic region cipC-celf is indicated by arrows. The upward arrow indicates the predicted signal sequence cleavage site.

al., 1991; GenBank accession number L32742); and (iii) the cellobiohydrolase $\mathrm{CbhB}$ (formerly termed CenE) of Cellulomonas fimi (Shen et al., 1995; Genbank accession number L38827). Apart from the signal peptides, CelS and $\mathrm{CelF}$ had $60 \%$ identical residues. The $\mathrm{C}$ terminus of both proteins contained the conserved, duplicated region typical of many clostridial cellulases and hemicellulases. Excluding the duplicated region, the sequences of CelF and of the C-terminal domain of Cald. saccharolyticum CelA were $65 \%$ identical, whereas the sequences of $\mathrm{CelF}$ and of CbhB of Cell. fimi were only $57 \%$ identical. Fig. 3 illustrates the similarity between CelF, CelS and the Cterminal domain of CelA. Similarities were also observed with the available $\mathrm{N}$-terminal sequence of Clostridium stercorarium Avicelase II (Bronnenmeier et al., 1991) (45\% identity among 33 residues). The similarity between residues 578-604 of CelF and residues 49-76 of an endoglucanase of Bacteroides ruminicola (Matsushita et al., 


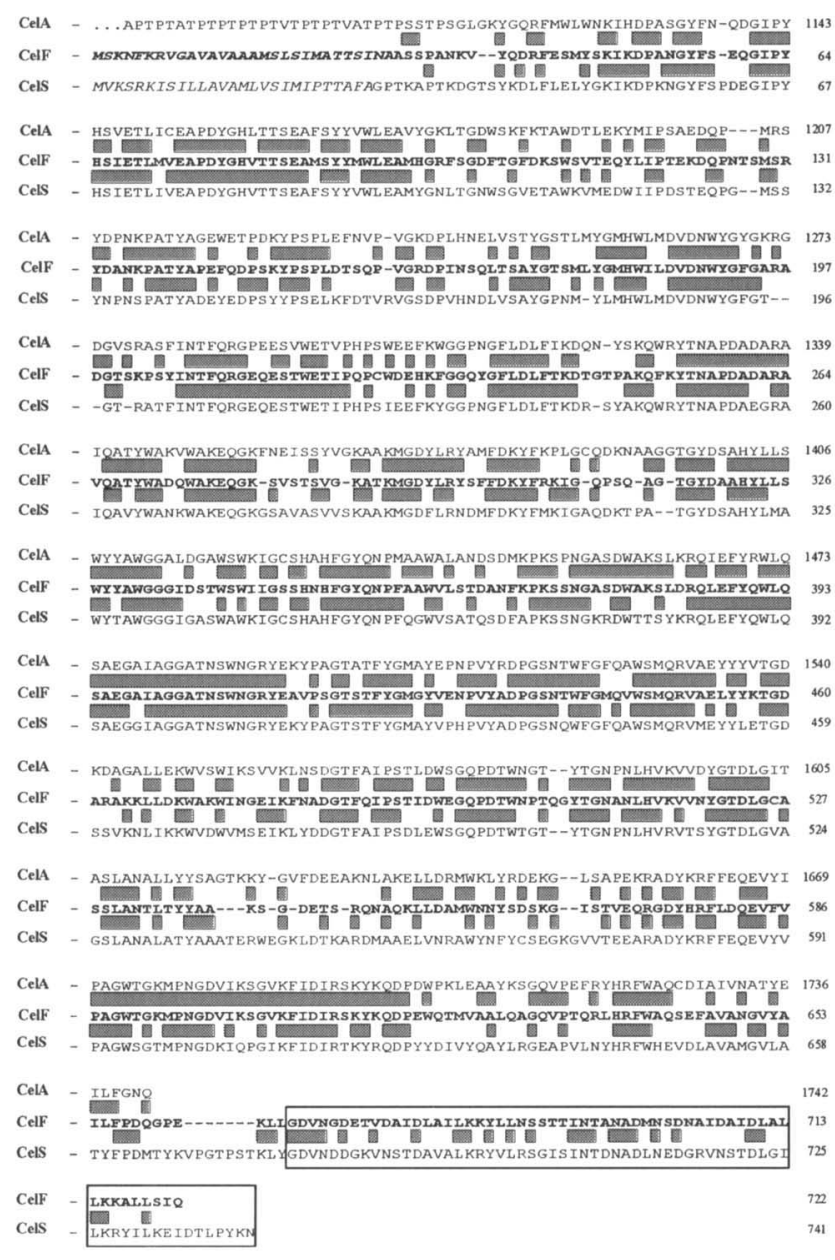

Fig. 3. Protein sequence comparisons between CelA from Cald. saccharolyticum, and CelF and CelS from Clost. thermocellum. The amino acid sequence of the CelA protein from Cald. saccharolyticum was obtained from the GenBank database (accession number L32742). Amino acids which are identical in both the mature proteins and CelF are denoted by shaded boxes. Amino acids belonging to the signal sequences are given in italics. The C-terminal clostridial conserved reiterated sequences are boxed.

1991) has been pointed out previously (Bagnara-Tardif $e t$ al., 1992).

\section{Sequence analysis of the region preceding celF}

The $3^{\prime}$ region of an ORF was found upstream from celF. The intergenic $116 \mathrm{bp}$ region includes an inverted repeated sequence extending over $35 \mathrm{nt}[\Delta G=-30 \mathrm{kcal}$ $\left.\mathrm{mol}^{-1}\left(-126 \mathrm{~kJ} \mathrm{~mol}^{-1}\right)\right]$. This structure might constitute either a terminator or an intercistronic regulatory element. The predicted translational product of the preceding ORF showed $45 \%$ identity with the C-terminal sequence of CbpA, the cellulosome scaffolding protein from Clostridium cellulovorans (Shoseyov et al., 1992) (Fig. 4), where the same organization of hydrophilic and hydrophobic domains was observed. This ORF was called cipC, by analogy with the cip $A$ gene encoding the cellulosome- integrating protein of Clost. thermocellum. The reiterated sequence which is present at the $C$ terminus of $C i p A$ from Clost. thermocellum NCIB 10682 (Gerngross et al., 1993) was not observed at the $\mathrm{C}$ terminus of $\mathrm{CipC}$.

\section{Overproduction of the CelF protein in E. coli}

The expression phasmids pETFc and pETFp encoding CelFc and CelFp, respectively, were constructed to study the cytoplasmic and periplasmic forms of CelF in E. coli (Fig. 5). Both polypeptides carried an eight amino acid Cterminal extension including six histidine residues, and could be purified by performing $\mathrm{Ni}^{2+}$ affinity chromatography. A methionine residue occurs prior to the native sequence in the $\mathrm{N}$-terminal sequence of the periplasmic mature CelFp protein.

In order to analyse the expression, the solubility and the localization of the recombinant proteins, crude cell extracts, and soluble and insoluble fractions were examined by SDS-PAGE. As shown in Fig. 6(a), CelFc and CelFp were both produced in soluble (lanes 3 and 8) and insoluble (lanes 4 and 9 ) forms. The inclusion bodies could be dissolved in $8 \mathrm{M}$, but not in $6 \mathrm{M}$ urea. CelFc, but not CelFp, was degraded to a smaller peptide with a molecular mass of about $45 \mathrm{kDa}$. Like CelFp and CelFc, the $45 \mathrm{kDa}$ species could be purified by $\mathrm{Ni}^{2+}$ affinity chromatography, indicating that it was derived from the C-terminal region of CelFc. Transmission electron microscopy analysis of thin sections of induced BL21(DE3)[pETFc] and BL21(DE3)[pETFp] showed in both cases the presence of inclusion bodies (Fig. 7). This was quite surprising, since periplasmic inclusion bodies have rarely been reported (Bernadac et al., 1987). Ribosomes were excluded from some parts of the cytoplasm (Fig. 7b) because of the presence of aggregated heterologous proteins. Interestingly, these showed up in the form of less electron-dense aggregates than the periplasmic inclusion bodies or than the BL21(DE3)[pETFc] cytoplasmic inclusion bodies. The composition of the CelFp aggregates was analysed by protein sequencing. Insoluble material from strain BL21(DE3)[pETFp] was fractionated by SDS-PAGE (10\% acrylamide) and the $\mathrm{N}$-terminal amino acid sequence of the band corresponding to CelF was determined. Two different N-terminal sequences were obtained. The first sequence corresponded to the expected $\mathrm{N}$-terminal sequence of the mature protein (approx. $50 \%$ of the proteins analysed) and the second sequence corresponded to the $\mathrm{N}$-terminal sequence of the PelB signal sequence. This indicated that the signal peptide was correctly removed from a portion of the proteins, but that a large fraction of the CelF (approx. 50\%) was not processed and probably not exported into the periplasmic space. It could therefore be assumed that under these induction conditions, the export machinery was overloaded, which led the precursor form of CelFp to accumulate inside the cytoplasm as observed in Fig. 7(b). The different appearance of cytoplasmic aggregates of CelFp and CelFc might be correlated with the lack of CelFp degradation. 

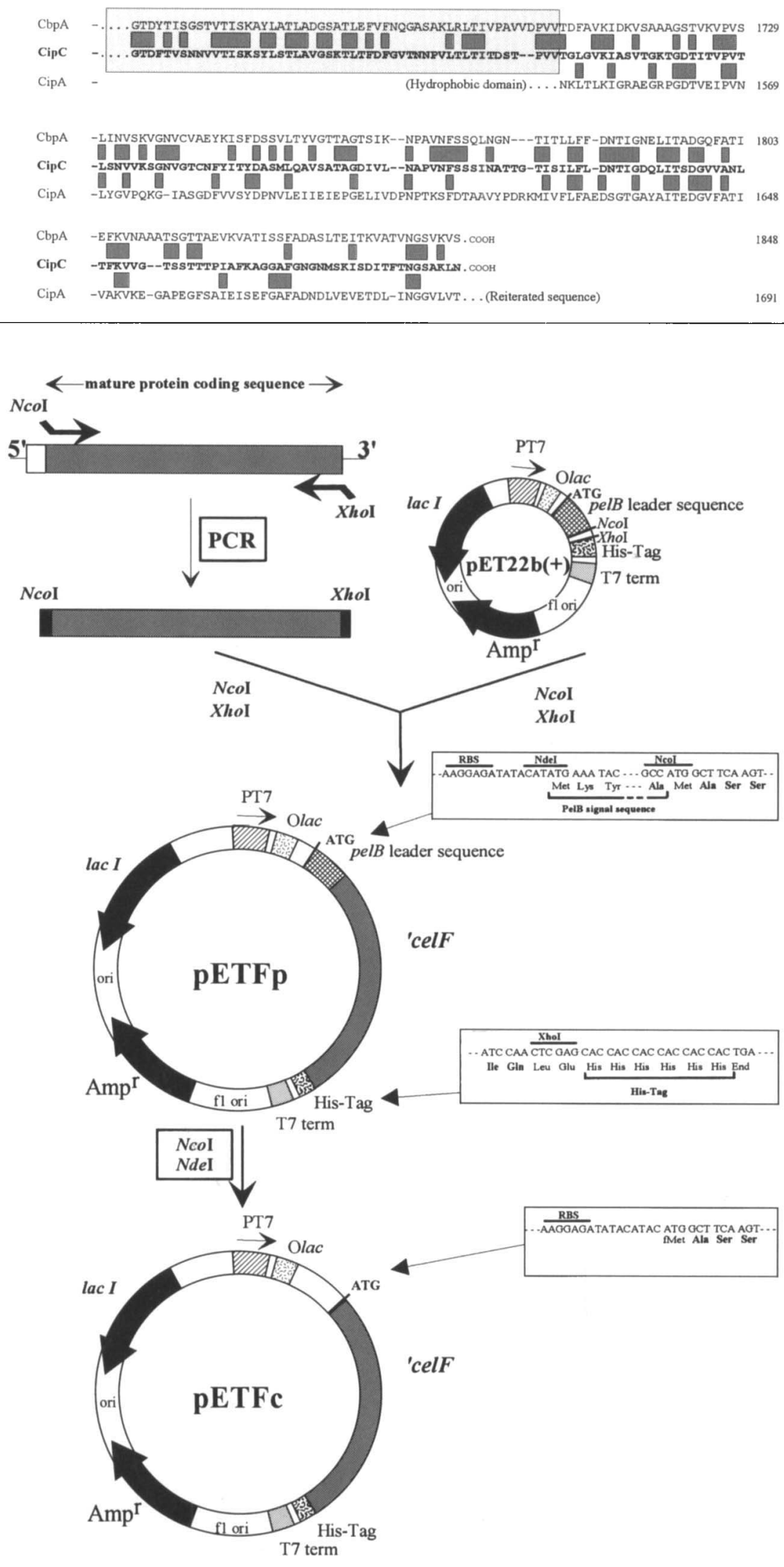

Fig. 4. Amino acid identities between the Cterminal hydrophobic domains of the scaffolding proteins CpbA from Clost. cellulovorans, CipC from Clost. cellulolyticum and CipA from Clost. thermocellum. The hydrophilic domains of CbpA from Clost. cellulovorans and CipC are shaded light grey. Gaps have been introduced to show the similarities between the proteins. Identical amino acids are denoted by dark grey shaded boxes.
Fig. 5. Construction of expression phasmids pETFp and PETFc. Only the restriction sites used for the construction are shown. Boxes contain details of the upstream and downstream in-frame fusions. Amino acids in bold characters are from Celf and those in light characters originate from the construction. Details are given in Methods.
The culture conditions were optimized so that mature CelFp could be purified in soluble form from BL21(DE3)[pETFp] using the osmotic shock procedure.
We first checked that $40 \mu \mathrm{M}$ IPTG was sufficient to achieve complete induction. Both secretion efficiency and protein solubility have been found to depend on cell 
(a)

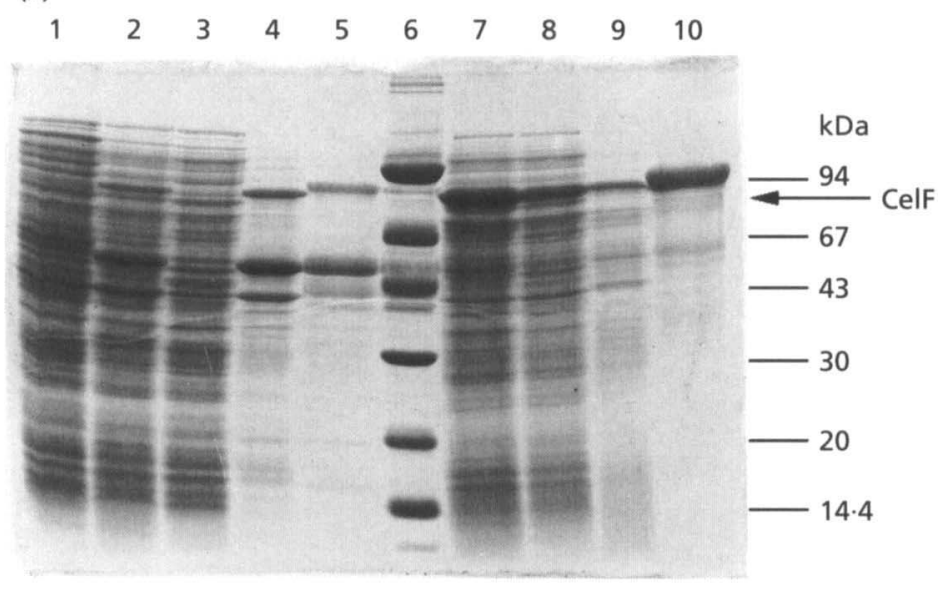

(b)

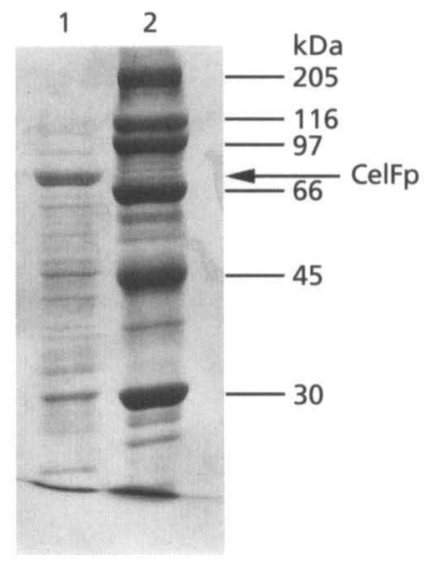

Fig. 6. (a) SDS-PAGE analysis of induced E. coli BL21(DE3)[pETFC] and E. coli BL21(DE3)[pETFp]. Proteins from $80 \mu l$ culture were separated by SDS-PAGE $(10 \%$ acrylamide) and stained with Coomassie Blue. Lanes: 1 , cell extract of strain BL21(DE3); 2-5, strain BL21(DE3)[pETFc]; 7-10, strain BL21(DE3)[pETFp]; 2 and 7, cell extracts; 3 and 8, soluble fractions; 4 and 9 , insoluble fractions resuspended in an equivalent volume of water; 5 and 10, granules washed in $6 \mathrm{M}$ urea and dissolved in an equivalent volume of $8 \mathrm{M}$ urea. (b) SDS-PAGE analysis of $10 \mu \mathrm{l} 50$-fold concentrated periplasmic fraction (lane 1). Lanes 6 (a) and 2 (b) contain marker proteins with molecular masses indicated on the right. The arrow indicates the position of CelF at 78/80 kDa.

density and induction temperature (LaVallie et al., 1993; Stader et al., 1990; Totsuka \& Fukazawa, 1993). To investigate the influence of induction temperature and stage of growth at the time of induction, cultures were incubated at $37{ }^{\circ} \mathrm{C}$ until the desired $\mathrm{OD}_{600}$ was reached. When necessary, the culture was allowed to equilibrate at the desired induction temperature for $30 \mathrm{~min}$ before adding $40 \mu \mathrm{M}$ IPTG. The culture was then incubated for $2 \mathrm{~h}$ at $37^{\circ} \mathrm{C}$, or overnight when expression was performed at $17^{\circ} \mathrm{C}$. To assess the expression and solubility of CelFp, the cell pellets were subjected to osmotic shock treatments (see Methods). After the final shock, the supernatants and pellets were analysed by SDS-PAGE, and the cellulase activity tested. The soluble activity released by osmotic shock from cultures induced at $17{ }^{\circ} \mathrm{C}$ was four- to ninefold greater than from those induced at $37^{\circ} \mathrm{C}$ (Table 1). At $17^{\circ} \mathrm{C}$, the total activity released increased in proportion to the $\mathrm{OD}_{600}$ at the time of induction, probably due to the fact that a larger number of cells produced the heterologous protein. In fact, $E$. coli cells do not grow satisfactorily at $17^{\circ} \mathrm{C}$ and after overnight induction, the biomass obtained had increased only twofold. Cell lysis occurred during longer induction times. The low cellulase activity in the $37^{\circ} \mathrm{C}$ shock supernatant might be attributable to the fact that most of the protein probably partitioned into large insoluble inclusion bodies which were not expelled from the periplasm during the osmotic shock procedure.

\section{Enzymic activity of soluble Celfp}

The expression of pETFp in E. coli BL21(DE3) after overnight incubation at $17{ }^{\circ} \mathrm{C}$ in the presence of $40 \mu \mathrm{M}$ IPTG yielded soluble active CelFp. As expected, the BL21(DE3) transformed with the expression vector
pET22b $(+)$ did not contain any detectable cellulase activity when grown in either the presence or absence of IPTG.

Fiftyfold concentrated final shock supernatant (Fig. 6b) was used to test the ability of the enzyme to hydrolyze various $\beta-1,4$ glycans. CelFp was able to hydrolyse various cellulose types, especially amorphous cellulose (Fig. 8). This enzyme showed very poor activity however on CMcellulose, a substituted amorphous cellulose substrate, which clearly differentiates it from the classical endoglucanases (Fierobe et al., 1991, 1993). Whereas measures performed after $24 \mathrm{~h}$ in the presence of Avicel showed that a linear increase in the reducing sugar released had occurred (data not shown), the hydrolysis reaction appeared to be blocked after only a few minutes in the case of CM-cellulose. No activity was observed on $p$-NPcellobioside, $p$-NP-glucoside or $p$-NP-lactoside (less than $10^{-5} \mathrm{IU} \mathrm{ml}^{-1}$ ), or on xylan (less than $10^{-4} \mathrm{IU} \mathrm{ml}^{-1}$ ).

\section{DISCUSSION}

Madarro et al. (1991) have recently established that the Avicel-adsorbed fraction of the Clost. cellulolyticum complex consists mainly of three major components. Two of them (the $160 / 170 \mathrm{kDa}$ and the $72 \mathrm{kDa}$ components) do not show any detectable activity on CM-cellulose and xylan, and the third one $(95 \mathrm{kDa})$ is strongly active on $\mathrm{CM}$-cellulose. The largest component is assumed to be the scaffolding protein, whose gene lies upstream from celF and has been partially cloned. Its molecular mass is in good agreement with those of similar clostridial scaffolding proteins. CelF might constitute the $72 \mathrm{kDa}$ major component of the Clost. cellulolyticum cellulosome, which did not exhibit any detectable activity on CMcellulose or xylan (Madarro et al., 1991). 

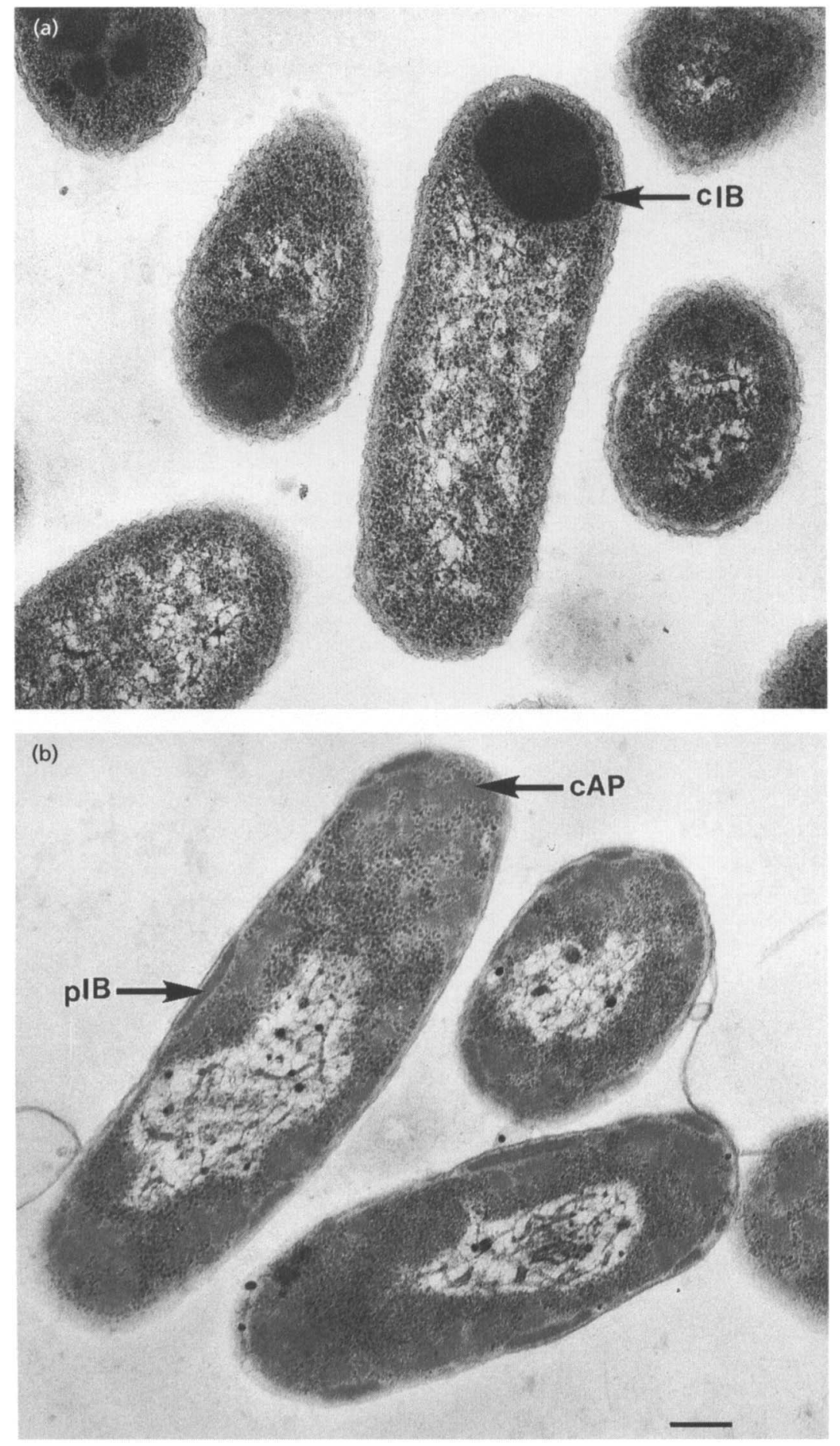

Fig. 7. Electron micrographs of thin sections of strain BL21(DE3)[pETFc] (a) and $B L 21(D E 3)[p E T F p]$ (b). Cells were grown at $37^{\circ} \mathrm{C}$ in LB medium containing $100 \mu \mathrm{g}$ ampicillin $\mathrm{ml}^{-1}$. ClB, cytoplasmic inclusion body; pIB, periplasmic inclusion body; CAP, cytoplasmic aggregated proteins. Bar, $0.2 \mu \mathrm{m}$.
CelF is similar to the catalytic core of several enzymes belonging to the cellulase family $\mathrm{L}$ (Shen et al., 1994) [family 48 of glycosyl hydrolases (Henrissat \& Bairoch, 1993; B. Henrissat, personal communication)]. The cellulases of this family whose properties have been investigated to date include the following three proteins: Clost. stercorarium Avicelase II (Bronnenmeier et al., 1991), Clost. thermocellum CelS/S8 (Morag et al., 1991; Kruus et al., 1995b), and Cell. fimi CbhB (formerly termed CenE)
(Shen et al.,1995). The activity of these three enzymes is highest on amorphous cellulose, and much lower if detectable on CM-cellulose and not detectable at all on aryl- $\beta$-D-cellobiosides. The same pattern was observed with CelF, whose activity on CM-cellulose appeared to be blocked after a few minutes. This might be due to CelF being inhibited by the presence of carboxymethyl groups on the substituted cellulose. It is therefore plausible that CelF might be a recurrently acting enzyme. 
Table 1. Effect of induction temperature and stage of growth at the time of induction on soluble periplasmic CelFp production

\begin{tabular}{|lcccc|}
\hline \multirow{2}{*}{ Parameter } & \multicolumn{4}{c|}{ Induction temp. $\left({ }^{\circ} \mathbf{C}\right)$} \\
\cline { 2 - 5 } & $\mathbf{3 7}$ & $\mathbf{1 7}$ & $\mathbf{1 7}$ & $\mathbf{1 7}$ \\
\hline $\mathrm{OD}_{600}$ of culture at time of induction & $2 \cdot 2$ & $1 \cdot 6$ & $2 \cdot 0$ & $2 \cdot 4$ \\
$\mathrm{OD}_{600}$ of harvested culture & $4 \cdot 0$ & $3 \cdot 0$ & $4 \cdot 0$ & $5 \cdot 0$ \\
Cellulase activity [IU (l broth) $\left.)^{-1}\right]^{*}$ & $0 \cdot 5$ & $2 \cdot 0$ & $3 \cdot 9$ & $4 \cdot 3$ \\
\hline
\end{tabular}

* Activity of the periplasmic fraction, obtained by osmotic shock from 11 broth, on swollen Avicel (see Methods).

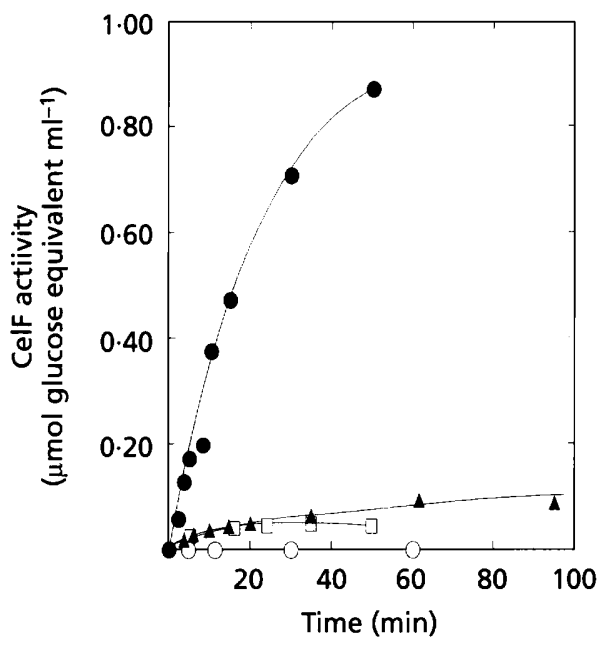

Fig. 8. Activity of CelF on various cellulosic substrates. In all the assays, $300 \mu \mathrm{l} 50$-fold concentrated periplasmic fraction $(1.5 \mathrm{mg}$ $\mathrm{ml}^{-1}$ ) diluted in $1 \mathrm{ml}$ was used. Each data point represents the mean of at least three values which did not vary more than $15 \%$ from the mean. O. Swollen Avicel; $\triangle$, Avicel; $\square, C M-$ cellulose; $O$, xylan. Activity is expressed as $\mu \mathrm{mol} D$-glucose equivalent released ( $\mathrm{ml}$ diluted enzyme $)^{-1}$.

Avicelase II and S8 has been reported to show significant xylanase activity (Bronnenmeier et al., 1991; Morag et al., 1991), whereas CelS, CbhB and CelF did not hydrolyse xylan. In the case of CelS, which was purified from aggregated recombinant protein (Wang et al., 1994; Kruus et al., 1995 b), the possibility that a loss of xylanase activity may have occured in the course of renaturation cannot be ruled out. However, Avicelase II and S8 were both purified from whole cellulase systems including xylanases, and the xylanolytic activity of the preparation may have been due to contamination with high specific activity xylanases. The absence of xylanase activity in CelF obtained in soluble form from BL21(DE3)[pETFp] supports this interpretation.

The possibility of obtaining CelF in undenatured form from a recombinant clone should therefore open the way to characterizing the true properties of the enzyme in detail. In particular, if the identity of CelF with one of the three major cellulosome components is confirmed, it will be of interest to test its ability to degrade crystalline cellulose synergistically with the purified endoglucanases and/or CipC.

Some indications on the essential role of this kind of enzyme in the synergistic mechanism of cellulose degradation have been obtained by Wu \& Demain (1988) and Kruus et al. (1995a), working on CipA (then termed $\mathrm{S}_{\mathrm{L}}$ ) and CelS (then termed $\mathrm{S}_{\mathrm{S}}$ ) of Clost. thermocellum, and by Creuzet et al. (1983) with an endoglucanase and an exoglucanase of Clost. stercorarium.

\section{ACKNOWLEDGEMENTS}

We thank the 'Service de Séquençage' (IFRC 1000, CNRS, Marseille) for performing the N-terminal Edman sequencing of CelFp. We are grateful to Vincent Méjean and Marc Rousset for helpful discussions and to Jessica Blanc for correcting the English manuscript.

This research was supported by grants from the Centre National de la Recherche Scientifique and the Université de Provence.

\section{REFERENCES}

Altschul, S. F., Gish, W., Miller, W., Myers, E. W. \& Lipman, D. J. (1990). Basic local alignment search tool. J Mol Biol 215, 403-410.

Bagnara-Tardif, C., Gaudin, C., Bélaich, A., Hoest, P., Citard, T. \& Bélaich, J. P. (1992). Sequence analysis of a gene cluster encoding cellulases from Clostridium cellulolyticum. Gene 119, 17-28.

Bélaich, A., Fierobe, H. P., Baty, D., Busetta, B., Bagnara-Tardif, C., Gaudin, C. \& Bélaich, J. P. (1992). The catalytic domain of endoglucanase A from Clostridium cellulolyticum, effects of arginine 79 and histidine 122 mutations on catalysis. J Bacteriol 174, 4677-4682.

Bernadac, A., Bolla, J. M., Lazdunski, C., Inouye, M. \& Pages, J. M. (1987). Precise localization of an overproduced periplasmic protein in Escherichia coli, use of double immuno-gold labelling. Biol Cell 61, 141-147.

Bronnenmeier, K., Rucknagel, K. P. \& Staudenbauer, W. L. (1991). Purification and properties of a novel type of exo-1,4- $\beta$-glucanase (Avicelase II) from the cellulolytic thermophile Clostridium stercorarium. Eur J Biochem 200, 379-385.

Creuzet, N., Berenger, J. F. \& Frixon, C. (1983). Characterization of exoglucanase and synergistic hydrolysis of cellulose in Clostridium stercorarium. FEMS Microbiol Lett 20, 347-350.

Ducros, V., Czjzek, M., Bélaich, A., Gaudin, C., Fierobe, H. P., Bélaich, J. P., Davies, G. J. \& Haser, R. (1995). Crystal structure of the catalytic domain of a bacterial cellulase belonging to family 5 . Structure 3, 939-949.

Engebrecht, J., Brent, R. \& Kaderbhai, M. A. (1991). In Current Protocols in Molecular Biology, pp. 1·6.1-1·6.10. Edited by F. M. Ausubel, R. Brent, R. E. Kingston, D. D. Moore, J. G. Seidman, J. A. Smith \& K. Struhl. USA: Greene Publishing Associates \& John Wiley.

Faure, E., Bélaich, A., Bagnara, C., Gaudin, C. \& Bélaich, J. P. (1987). Characterization of the cellulolytic system of Clostridium cellulolyticum. In Biomass for Energy and Industry (4th European Communities Conference), pp. 717-721. Edited by G. Grassi, B. Delmon, J. F. Molle \& H. Zibetta. London \& New York: Elsevier Applied Science.

Faure, E., Bélaich A., Bagnara C., Gaudin C. \& Bélaich J. P. (1989). 
Sequence analysis of the Clostridium cellulolyticum endoglucanase-Aencoding gene, celCCA. Gene 84, 39-46.

Fierobe, H. P., Gaudin, C., Bélaich, A., Loutfi, M., Faure, E., Bagnara, C., Baty, D. \& Bellaich, J. P. (1991). Characterization of endoglucanase A from Clostridium cellulolyticum. I Bacteriol 173, 7956-7962.

Fierobe, H. P., Bagnara-Tardif, C., Gaudin, C., Guerlesquin, F., Sauve, P., Bélaich, A. \& Bélaich, J. P. (1993). Purification and characterization of endoglucanase $C$ from Clostridium cellulolyticum - catalytic comparison with endoglucanase A. Eur J Biochem 217, $557-565$.

Fujino, T., Béguin, P. \& Aubert, J. P. (1993a). Organization of a Clostridium thermocellum gene cluster encoding the cellulosomal scaffolding protein CipA and a protein possibly involved in the attachment of the cellulosome to the cell surface. $J$ Bacterioi $\mathbf{1 7 5}$, 1891-1899.

Fujino, T., Karita, S. \& Ohmiya, K. (1993b). Nucleotide sequences of the $c e l B$ gene encoding endo-1,4- $\beta$-glucanase-2, ORF1 and ORF2 forming a putative cellulase gene cluster of Clostridium josui. $J$ Ferment Bioeng 76, 243-250.

Gerngross, U. T., Romaniec, M. P. M., Kobayashi, T., Huskisson, N. S. \& Demain, A. L. (1993). Sequencing of a Clostridium thermocellum gene ( $c i p A)$ encoding the cellulosomal SL-protein reveals an unusual degree of internal homology. Mol Microbiol 8, 325-334.

Giallo, J., Gaudin, C., Bélaich, J. P., Petitdemange, E. \& Caillet, F. (1983). Metabolism of glucose and cellobiose by cellulolytic mesophilic Clostridium sp. strain H10. Appl Environ Microbiol 45, 843-849.

Giallo, J., Gaudin, C. \& Bélaich, J. P. (1985). Metabolism and solubilization of cellulose by Clostridium cellulolyticum H10. Appl Environ Microbiol 49, 1216-1221.

Grépinet, O., Chebrou, M. C. \& Béguin, P. (1988). Nucleotide sequence and deletion analysis of the xylanase gene ( $x y n Z)$ of Clostridium thermocellum. J Bacteriol 170, 4582-4588.

Henrissat, B. \& Bairoch, A. (1993). New families in the classification of glycosyl hydrolases based on amino acid sequence similarities. Biochem J 293, 781-788.

Kruus, K., Lua, A. C., Demain, A. L. \& Wu, J. H. D. (1995a). The anchorage function of CipA (CelL), a scaffolding protein of the Clostridium thermocellum cellulosome. Proc Natl Acad Sci USA 92, 9254-9258.

Kruus, K., Wang, W. K., Ching, J. \& Wu, J. H. D. (1995b). Exoglucanase activities of the recombinant Clostridium thermocellum CelS, a major cellulosome component. J Bacteriol 177, 1641-1644.

Lamed, R., Setter, E. \& Bayer, E. A. (1983a). Characterization of a cellulose-binding cellulase-containing complex in Clostridium thermocellum. J Bacteriol 156, 828-836.

Lamed, R., Setter, E., Kenig, R. \& Bayer, E. A. (1983b). The cellulosome, a discrete cell surface organelle of Clostridium thermocellum which exhibits separate antigenic, cellulose-binding and various cellulolytic activities. Biotechnol Bioeng Symp 13, 163--181.

LaVallie, E. R., DiBlasio, E. A., Kovacic, S., Grant, K. L., Schendel, P. F. \& McCoy, J. M. (1993). A thioredoxin gene fusion expression system that circumvents inclusion body formation in the E. coli cytoplasm. Bio/Technology 11, 187-193.

Lüthi, E., Bahna Jasmat, N., Grayling, R. A., Love, D. R. \& Bergquist, P. L. (1991). Cloning, sequence analysis and expression in Eschericbia coli of a gene coding for a $\beta$-mannanase from the extremely thermophilic bacterium 'Caldocellum saccharolyticum'. Appl Environ Microbiol 57, 694-700.
Madarro, A., Pena, J. L., Lequerica, J. L., Vallés, S., Gay, R. \& Flors, A. (1991). Partial purification and characterization of the cellulases from Clostridium cellulolyticum H10. J Chem Technol Biotechnol 52, 393-406.

Matsushita, O., Russel, J. B. \& Wilson, D. B. (1991). A Bacteroides rumicola $1,4-\beta$-D-endoglucanase is encoded in two reading frames. J Bacteriol 173, 6919-6926.

Morag, E., Halevy, I., Bayer, E. A. \& Lamed, R. (1991). Isolation and properties of a major cellobiohydrolase from the cellulosome of Clostridium thermocellum. J Bacteriol 173, 4155-4162.

Morag, E., Bayer, E. A., Hazlewood, G. P., Gilbert, H. J. \& Lamed, R. (1993). Cellulase $S_{\mathrm{s}}(\mathrm{CelS})$ is synonymous with the major cellobiohydrolase (subunit S8) from the cellulosome of Clostridium thermocellum. Appl Biochem Biotechnol 43, 147-152.

Ochman, H., Medhora, M. M., Garza, D. \& Hartl, D. L. (1990). Amplification of flanking sequences by inverse PCR. In PCR Protocols, pp. 219-227. Edited by M. A. Innis, D. H. Gelfand, J. J. Sninsky \& T. J. White. San Diego: Academic Press.

Park, J. T. \& Johnson, M. S. (1949). A submicrodetermination of glucose. J Biol Chem 181, 149-151.

Perlman, D. \& Halvorson, H. O. (1983). A putative signal peptidase recognition site and sequence in eucaryotic and procaryotic signal peptides. J Mol Biol 167, 391-409.

Petitdemange, E., Caillet, F., Giallo, J. \& Gaudin, C. (1984). Clostridium cellulolyticum sp. nov. a cellulolytic mesophilic species from decayed grass. Int J Syst Bacteriol 34, 155-159.

Quiviger, B., Franche, C., Lutfalla, G., Rice, D., Haselkorn, R. \& Elmerich, C. (1982). Cloning of nitrogen fixation (nif) gene cluster of Azospirillum brasilense. Biocbimie 64, 495-502.

Roig, V., Fierobe, H. P., Ducros, V., Czjzek, M., Bélaich, A., Gaudin, C., Bélaich, J. P. \& Haser, R. (1993). Crystallization and preliminary $\mathrm{X}$-ray analysis of the catalytic domain of endoglucanase A from Clostridium cellulolyticum. J Mol Biol 233, 325-327.

Salamitou, S., Tokatlidis, K., Béguin, P. \& Aubert, J. P. (1992). Involvement of separate domains of the cellulosomal protein S1 of Clostridium thermocellum in binding to cellulose and in anchoring of catalytic subunits to the cellulosome. FEBS Lett 304, 89-92.

Sanger, F., Nicklen, S. \& Coulson, A. R. (1977). DNA sequencing with chain-terminating inhibitors. Proc Natl Acad Sci USA 74, 5463-5467.

Schimming, S., Schwarz, W. H. \& Staudenbauer, W. L. (1991). Properties of a thermoactive $\beta-1,3$ glucanase (lichenase) from Clostridium thermocellum expressed in Escherichia coli. Biochem Biopbys Res Comm 177, 447-452.

Shen, H., Tomme, P., Meinke, A., Gilkes, N. R., Kilburn, D. G. Warren, R. A. J. \& Miller R. C., Jr (1994). Stereochemical course of hydrolysis catalysed by Cellulomonas fimi CenE, a member of a new family of $\beta-1,4$-glucanases. Biochem Biophys Res Commun 199, $1223-1228$.

Shen, H., Gilkes, N. R., Kilburn, D. G., Miller R. C., Jr \& Warren, R. A. J. (1995). Cellobiohydrolase B, a second exo-cellobiohydrolase from the cellulolytic bacterium Cellulomonas fimi. Biocbem $J$ 311, 67-74.

Shima, S., Igararashi, Y. \& Kodama, T. (1991). Nucleotide sequence analysis of the endoglucanase-encoding gene, celCCD, of Clostridium cellulolyticum. Gene 104, 33-38.

Shoseyov, O., Takagi, M., Goldstein, M. A. \& Doi, R. H. (1992). Primary sequence analysis of Clostridium cellulovorans cellulose binding protein A. Proc Natl Acad Sci US A 89, 3483-3487.

Stader, J. A. \&. Silhavy, T. J (1990). Engineering Escherichia coli to secrete heterologous gene products. Meth Enzymol 185, 166-187. 
Tokatlidis, K., Salamitou, S., Béguin, P., Dhurjati, P. \& Aubert, J. P. (1991). Interaction of the duplicated segment carried by Clostridium thermocellum cellulases with cellulosome components. FEBS Lett 291, 185-188.

Totsuka, A. \& Fukazawa, C. (1993). Expression and mutation of soybean $\beta$-amylase in Escherichia coli. Eur J Biochem 214, 787-794.

Wang, W. K., Kruus, K. \& Wu, J. H. D. (1993). Cloning and DNA sequence of the gene coding for Clostridium thermocellum cellulase Ss (CelS), a major cellulosome component. J Bacteriol 175, 1293-1302.

Wang, W. K., Kruus, K. \& Wu, J. H. D. (1994). Cloning and expression of the Clostridium thermocellum celS gene in Escherichia coli. Appl Microbiol Biotechnol 42, 346-352.
Wood, T. M. (1988). Preparation of crystalline, amorphous, and dyed cellulase substrates. Meth Enzymol 160, 19-23.

Wu, J. H. D. \& Demain, A. L. (1988). Proteins of the Clostridium thermocellum cellulase complex responsible for degradation of crystalline cellulose. In Biochemistry and Genetics of Cellulose Degradation (FEMS Symposium no. 43), pp. 117-131. Edited by J. P. Aubert, P. Béguin \& J. Millet. London \& New York: Academic Press.

Received 2 October 1995; revised 1 December 1995; accepted 7 December 1995. 